City University of New York (CUNY)

CUNY Academic Works

Publications and Research

CUNY Graduate School of Public Health \&

Health Policy

1995

\title{
A Population-Based Serologic Survey of Immunity to Tetanus in the United States
}

Peter J. Gergen

National Institutes of Health

Geraldine M. McQuillan

Centers for Disease Control and Prevention

Michele Kiely

CUNY School of Public Health

Trena M. Ezzati-Rice

Centers for Disease Control and Prevention

Roland W. Sutter

Centers for Disease Control and Prevention

See next page for additional authors

\section{How does access to this work benefit you? Let us know!}

More information about this work at: https://academicworks.cuny.edu/sph_pubs/14

Discover additional works at: https://academicworks.cuny.edu

This work is made publicly available by the City University of New York (CUNY).

Contact: AcademicWorks@cuny.edu 
Authors

Peter J. Gergen, Geraldine M. McQuillan, Michele Kiely, Trena M. Ezzati-Rice, Roland W. Sutter, and Gabriel Virella 


\title{
The New England Journal of Medicine
}

CCopyright, 1995, by the Massachusetts Medical Society

\section{A POPULATION-BASED SEROLOGIC SURVEY OF IMMUNITY TO TETANUS IN THE UNITED STATES}

\author{
Peter J. Gergen, M.D., M.P.H., Geraldine M. MaQuillan, Ph.D., Michele Kiely, Dr.P.H., \\ Trena M. Ezzati-Rice, M.S., Roland W. Sutter, M.D., M.P.H.\&T.M., and Gabriel Virella, M.D., Ph.D.
}

\begin{abstract}
Background. Vaccination rates are frequently considered a surrogate measure of protection. To provide more accurate estimates, serum levels of antibody against tetanus were measured as part of the third $\mathrm{Na}$ tional Health and Nutrition Examination Survey (NHANES III), which studied a representative sample of the civilian, noninstitutionalized population of the United States.

Methods. We measured tetanus antitoxin using a solid-phase enzyme immunoassay in serum samples from 10,618 persons six years of age and older who were examined during phase 1 of NHANES III in 1988 to 1991.

Results. Overall, 69.7 percent of Americans six years of age and older had protective levels of tetanus antibodies $(>0.15 \mathrm{IU}$ per milliliter). The rate decreased from 87.7 percent among those 6 to 11 years of age to 27.8 percent among those 70 years of age or older. Among children 6 to 16 years of age, 82.2 percent had protective levels of tetanus antibodies, with little variation according to race or ethnicity. More men than women were immune (79.0
\end{abstract}

$\mathrm{V}$ ACCINES are the most cost-effective public health intervention. ${ }^{1}$ Children ${ }^{2}$ and the elderly ${ }^{3,4}$ are at risk for insufficient immunization coverage. Much effort has been spent attempting to increase the coverage among children. All 50 states have adopted laws requiring children to be vaccinated before they are admitted to school, ${ }^{5,6}$ and more than 96 percent of school-age children now receive three or more vaccinations with diphtheria and tetanus toxoids and pertussis vaccine (DTP) at school entry. ${ }^{2}$ Vaccination rates have historically been lower in preschool children less than five years of age (e.g., 70 to 80 percent), $)^{7-9}$ and the Childhood Immunization Initiative was created to increase the level of vaccination coverage in this age group. ${ }^{10}$

Vaccination rates are frequently considered a surrogate measure of protection. Serum levels of protective antibody are a more objective measure. The first phase

From the National Institute of Allergy and Infectious Diseases, National Institutes of Health, Bethesda, Md. (P.J.G.); National Center for Health Statistics, Centers for Disease Control and Prevention, Hyattsville, Md. (G.M.M., T.M.E.-R.); Maternal and Child Health Bureau, Health Resources Service Administration, Rockville, Md. (M.K.); National Immunization Program, Centers for Disease Control and Prevention, Atlanta (R.W.S.); and Department of Microbiology and Immunology, Medical University of South Carolina, Charleston (G.V.). Address reprint requests to Dr. Gergen at Solar, Rm. 4A29, 6003 Executive Blvd., MSC 7640, Bethesda, MD 20892-7640. percent vs. 62.4 percent). Mexican Americans had a significantly lower rate of immunity $(57.9$ percent, $\mathrm{P}<0.05)$ than either non-Hispanic whites (72.7 percent) or non-Hispanic blacks (68.1 percent). Those with a history of military service, higher levels of education, or incomes above the poverty level were more likely to have protective antibody levels. Although the prevalence of immunity declined rapidly starting at the age of 40 years, most of the 107 cases of tetanus (with 20 deaths) reported in 1989 and 1990 occurred in persons 60 years of age or older.

Conclusions. Despite the fact that effective vaccines against tetanus have been available since the 1940s, many Americans do not have immunity to tetanus, and the rates are lowest among the elderly. There is an excellent correlation between vaccination rates (96 percent) and immunity (96 percent) among six-year-olds. However, antibody levels decline over time, and one fifth of older children (10 to 16 years of age) do not have protective antibody levels. (N Engl J Med 1995;332:761-6.)

of the third National Health and Nutrition Examination Survey (NHANES III), conducted from 1988 to 1991, offered the opportunity to examine the prevalence of protective levels of tetanus antibody in a representative sample of the U.S. population and to identify subgroups susceptible to tetanus.

\section{Methods}

\section{Survey Design and Data Collection}

NHANES is a periodic national survey conducted by the National Center for Health Statistics of the Centers for Disease Control and Prevention (CDC). The survey is designed to provide national statistics on the health and nutritional status of the civilian, noninstitutionalized population through household interviews and standardized physical examinations conducted in special mobile examination centers. With a sample of approximately 40,000 persons two months of age or older, NHANES III has been divided into two three-year surveys (phase 1 and phase 2) so that national estimates can be produced for each three-year period as well as for the total six-year period. The survey was conducted from 1988 through 1994 in 89 randomly selected locations throughout the United States. Data presented here are from phase 1, which was conducted from October 1988 through October 1991.

NHANES III is based on a multistage probability-sample design. Children under 5 years of age, persons 60 years of age and older, Mexican Americans, and non-Hispanic blacks are included in the survey at a higher rate than other persons. To produce national estimates, the results for each person are adjusted or weighted to ac- 
count for the differential probabilities of selection and response. ${ }^{11}$ Details of the sample design have been published elsewhere. ${ }^{12}$

\section{Laboratory Methods}

The level of tetanus antitoxin was measured with a solid-phase enzyme immunoassay. Enzyme-immunoassay plates (Immulon I, Dynatech, Chantilly, Va.) were coated with tetanus toxoid by incubating them with tetanus toxoid (0.1 limit-of-flocculation unit per well; Wyeth-Ayerst Laboratories, Marietta, Ga.) diluted in $0.25 \mathrm{M}$ sodium carbonate and bicarbonate buffer, $\mathrm{pH}$ 9.6. Serum samples were routinely divided into two groups for testing. Serum samples from persons who were 50 years of age or older were assayed at dilutions ranging from $1: 10$ to $1: 200$, because of the high frequency of low antibody concentrations in older persons. All other samples were studied in dilutions ranging from 1:100 to $1: 12,800$. If the antibody concentration was too low to be detected at these dilutions, the assay was repeated with different ranges of dilutions, starting at 1:10. The antibody concentration for each sample was calculated by averaging the values obtained at three different dilutions. The methods have been described in detail elsewhere. ${ }^{13}$

The lower limit of detection for this assay is $0.001 \mathrm{IU}$ per milliliter. This is well below the level of antitoxin that is considered protective on enzyme immunoassay - 20.16 IU per milliliter. ${ }^{14}$ For all analyses in this report, protective levels of tetanus antitoxin are defined as those exceeding $0.15 \mathrm{IU}$ per milliliter. This value is considerably higher than the level of $0.01 \mathrm{IU}$ per milliliter that is used when antibody levels are determined by the neutralization assay in animals. Although the enzyme immunoassay is specific, sensitive, and considerably more accurate than the neutralization assay, the two assays yield different results at antibody levels below 0.2 IU per milliliter, probably because the enzyme immunoassay quantitates antibodies with low levels of neutralizing activity (e.g., IgM antibodies and low-affinity antibodies in general). According to Simonsen et al., ${ }^{14}$ antibody levels above 0.15 IU per milliliter on enzyme immunoassay can be assumed with reasonable confidence to be protective. Thus, we adopted this value as our cutoff level.

The tetanus-antitoxin assay was performed on serum collected from persons four years of age or older. Because of insufficient blood collection, tetanus antibodies were measured in only 31 percent of the children four and five years old. Consequently, all analyses are restricted to persons six years of age or older.

\section{Variables}

Three mutually exclusive racial and ethnic groups were created on the basis of the NHANES III sample design: non-Hispanic whites, non-Hispanic blacks, and Mexican Americans. Persons not included in one of these groups are included in estimates involving the total population.

A participant's age was defined as his or her age at the time of the household interview. Educational level was determined on the basis of the last completed year of schooling: elementary, post-elementary, high school, or college. For children 6 to 16 years of age, the head of household's level of education was used in the analyses of immunization status and educational level.

The poverty-index ratio was calculated by dividing the total family income by the poverty threshold adjusted for family size for the year of the interview, as determined by the Bureau of the Census. ${ }^{15-17}$ The total family income included total family wages, salaries, Social Security benefits, retirement benefits, and any other earnings received during the 12 months before the interview. A poverty-index ratio below 1 was considered to indicate poverty.

County population size was used to determine whether an area was urban or rural. Counties with populations of more than 1 million were defined as urban.

Data on military service were based on respondents' reports of service in the armed forces of the United States. Only women with no history of military service could be evaluated, because there were too few female veterans in the survey.

\section{Response Rates}

Of the 13,714 persons six years of age or older who were interviewed for the survey, 77.4 percent underwent a physical examination and consented to phlebotomy, from which enough serum was obtained to measure tetanus antitoxin. Response rates exceeded 81 percent for all age groups except for children 6 to 11 years old ( 57.2 percent) and persons 70 or more years old (72.4 percent). The response rate varied little according to the place of birth and the poverty-index ratio. Previous analyses of NHANES III data found that no apparent bias was introduced by a nonresponse. ${ }^{11,18}$

\section{Tetanus Surveillance}

A national surveillance of tetanus relies on the reporting of physician-diagnosed cases of tetanus to state and local health departments. State health departments report cases of tetanus on a weekly basis to the CDC through the National Notifiable Diseases Surveillance System. Supplemental clinical and epidemiologic information is submitted by reporting states to the National Immunization Program at the CDC. ${ }^{19}$ Data for 1989 and 1990 from the supplemental surveillance system were analyzed to determine the incidence of tetanus according to age in the United States.

\section{Statistical Analysis}

All prevalence estimates were weighted to account for oversampling, lack of response to the household interview, and lack of physical examination. Population estimates were based on weights stratified according to the Census Bureau's Current Population Survey for March 1990. ${ }^{11,12}$

Standard errors were calculated with SUDAAN, ${ }^{20}$ a family of statistical procedures for analysis of data from complex sample surveys. The direct method was used to adjust prevalence estimates for age in order to standardize comparisons. ${ }^{21}$ The reference population was the 1980 U.S. population. Multivariate analyses were performed with logistic regression. The weighted odds ratios and 95 percent confidence intervals were based on standard errors incorporating the complex sample design.

\section{RESUlTS}

\section{Relation of Age, Sex, Race, and Ethnicity to Levels of Tetanus Antibodies}

Overall, 69.7 percent of the U.S. population six years of age and older had protective levels of tetanus antibodies (age-adjusted value, 70.3 percent) (Fig. 1). The prevalence of immunity varied according to age, remaining above 80 percent for persons 6 through 39 years of age. Beginning at the age of 40 , the prevalence of immunity dropped sharply with increasing age, until it reached 27.8 percent in the group of respondents who were 70 or more years old (Fig. 1). A similar pattern was seen among non-Hispanic whites and nonHispanic blacks, whereas for Mexican Americans the prevalence of immunity began to decrease earlier.

For all racial and ethnic groups, men had significantly higher age-adjusted rates of immunity than women. The large differences in the rates between men and women 40 years of age and older accounted for most of this gap.

\section{Correlates of Immunity}

Because of the strong effect of age on the prevalence of immunity to tetanus, the analyses in Table 1 were adjusted for age in order to standardize the comparison between racial and ethnic groups. The unadjusted prevalence is presented for comparison. Non-Hispanic whites had the highest rate of immunity (72.7 percent), followed by non-Hispanic blacks (68.1 percent) and then by Mexican Americans (57.9 percent).

Poverty, defined as a poverty-index ratio of less than 

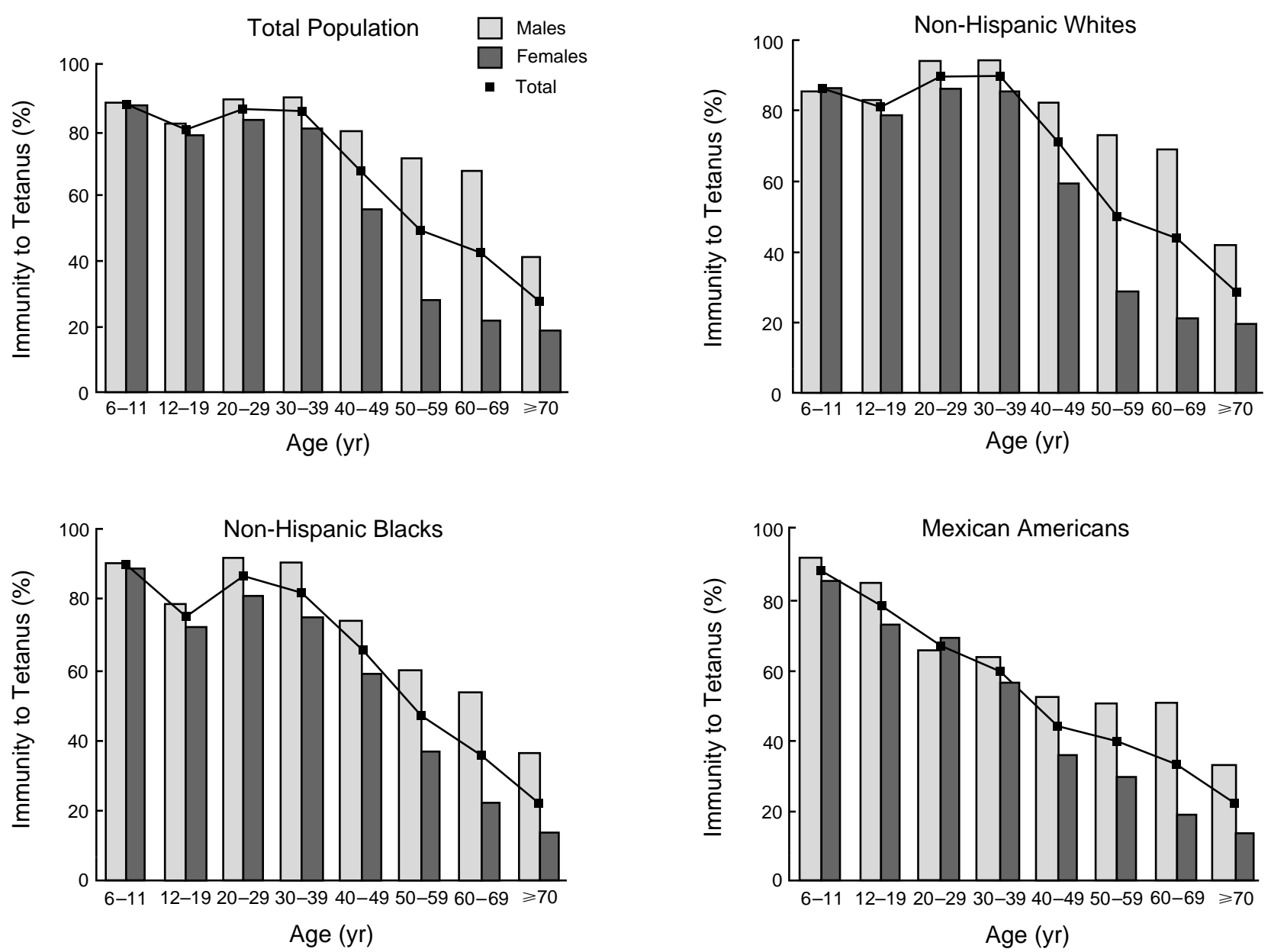

Figure 1. Age-Specific Prevalence of Immunity to Tetanus According to Racial and Ethnic Group in the NHANES III Population, 1988 to 1991.

1, was associated with a lower rate of immunity, except among non-Hispanic blacks. Birth outside the United States and lower educational status among persons at least 17 years of age were associated with lower rates of immunity. No consistent association with urban or rural residence was noted.

Among subjects who were at least 20 years of age, men with a history of military service had a higher rate of immunity to tetanus than men who were not veterans (Fig. 2), and the difference between groups increased with age. Women without a history of military service had lower levels of protection than either male veterans or male nonveterans.

\section{Multivariate Analysis}

Logistic-regression analysis was conducted to determine whether any variables were independent predictors of protective levels of tetanus antibodies. After adjustment for age, the following were all significant predictors of immunity to tetanus: male sex (odds ratio, 2.2; 95 percent confidence interval, 1.9 to 2.5), nonHispanic white race (odds ratio, 1.5; 95 percent confidence interval, 1.2 to 1.7 ), birth in the United States or Canada (odds ratio, 3.4; 95 percent confidence interval,
2.5 to 4.5 ), military service (odds ratio, 3.5; 95 percent confidence interval, 2.8 to 4.6 ), and some college education (odds ratio, $1.5 ; 95$ percent confidence interval, 1.3 to 1.8$)$.

\section{Prevalence of Immunity among Children 6 to 16 Years of Age}

Of the children 6 to 16 years of age, 82.2 percent had protective levels of tetanus antibodies. The prevalence of immunity to tetanus varied little according to racial or ethnic group (non-Hispanic whites, 81.8 percent; non-Hispanic blacks, 83.0 percent; Mexican Americans, 85.2 percent).

The rate of immunity to tetanus was approximately 96 percent in six-year-olds and 90 percent in children seven to nine years of age. For children 10 to 16 years of age, the rate dropped to 80 percent. There was little difference in this pattern among the three racial and ethnic groups.

The prevalence of immunity decreased as the length of time since the last tetanus immunization increased. Among children 6 to 16 years old who reported having been immunized less than one year before the interview, 94.9 percent were immune. This value dropped to 
Table 1. Unadjusted and Age-Adjusted Correlates of Immunity to Tetanus among NHANES III Participants Six Years of Age or Older, 1989 to $1991 . *$

\begin{tabular}{|c|c|c|c|c|c|}
\hline Correlate & Sample Size & $\begin{array}{l}\text { Total Population } \\
\quad(\mathrm{N}=10,618)\end{array}$ & $\begin{array}{l}\text { Non-Hispanic Whites } \\
\quad(\mathrm{N}=4383)\end{array}$ & $\begin{array}{l}\text { NON-HISPANIC BLACKS } \\
\qquad(\mathrm{N}=2621)\end{array}$ & $\begin{array}{l}\text { MEXICAN AMERICANS } \\
\quad(\mathrm{N}=3260)\end{array}$ \\
\hline & & \multicolumn{4}{|c|}{ percent ( 95 percent confidence interval) } \\
\hline Unadjusted & 10,618 & $69.7(67.9-71.5)$ & $71.0(69.3-72.7)$ & $71.0(68.5-73.5)$ & $63.7(61.2-66.2)$ \\
\hline Age-adjusted & 10,618 & $70.3(68.8-71.8)$ & $72.7(71.4-74.0)$ & $68.1(66.4-69.8)$ & $57.9(55.7-60.1)$ \\
\hline \multicolumn{6}{|l|}{ Sex } \\
\hline Male & 5,304 & $79.0(77.5-80.5)$ & $81.7(80.3-83.1)$ & $76.4(74.1-78.7)$ & $63.9(60.7-67.1)$ \\
\hline Female & 5,314 & $62.4(60.6-64.2)$ & $64.4(62.5-66.3)$ & $61.4(58.7-64.1)$ & $52.1(50.3-53.9)$ \\
\hline \multicolumn{6}{|l|}{ Poverty-index ratio } \\
\hline$<1$ & 2,437 & $65.0(62.4-67.6)$ & $67.9(63.5-72.3)$ & $68.8(66.1-71.5)$ & $51.1(48.3-53.9)$ \\
\hline$\geqslant 1$ & 8,181 & $70.9(69.1-72.7)$ & $73.1(71.5-74.7)$ & $67.9(65.7-70.1)$ & $60.8(58.0-63.6)$ \\
\hline \multicolumn{6}{|l|}{ Residence $\dagger$} \\
\hline Urban & 7,180 & $69.8(67.9-71.1)$ & $72.9(70.9-74.9)$ & $68.4(66.7-70.1)$ & $58.8(56.6-61.0)$ \\
\hline Rural & 3,290 & $71.7(70.6-72.8)$ & $72.8(71.9-73.7)$ & $66.2(63.3-69.1)$ & $55.8(53.2-58.4)$ \\
\hline \multicolumn{6}{|l|}{ Place of birth $\dagger$} \\
\hline U.S. or Canada & 8,663 & $72.8(71.5-74.1)$ & $73.3(71.8-74.8)$ & $69.2(67.9-70.5)$ & $69.3(66.8-71.8)$ \\
\hline Other & 1,914 & $52.5(48.3-56.7)$ & $60.7(53.8-67.6)$ & $50.3(42.0-58.6)$ & $47.6(44.6-50.6)$ \\
\hline \multicolumn{6}{|l|}{ Educational level } \\
\hline Elementary & 1,859 & $46.6(40.0-53.2)$ & $56.3(46.1-66.5)$ & $55.5(45.3-65.7)$ & $36.1(30.7-41.5)$ \\
\hline Post-elementary & 1,513 & $66.4(63.8-69.0)$ & $70.0(66.4-73.6)$ & $66.5(64.1-69.0)$ & $56.7(50.0-63.4)$ \\
\hline High school & 2,474 & $69.6(66.8-72.4)$ & $71.2(68.1-74.3)$ & $65.9(62.5-69.3)$ & $69.4(66.1-72.7)$ \\
\hline College & 2,372 & $74.3(71.9-76.7)$ & $75.9(73.8-78.0)$ & $68.4(64.2-72.6)$ & $70.5(62.7-78.3)$ \\
\hline
\end{tabular}

*Adjusted for age according to the 1980 U.S. Census

$\dagger$ Participants with missing data were not included in the analysis.

$\ddagger$ This analysis was limited to participants at least 17 years of age.

85.6 percent among those reporting that they had last been immunized 1 to 5 years before the interview, to 72.1 percent among those immunized 6 to 10 years before the interview, and to 69.4 percent among those immunized 11 or more years before the interview.

None of the risk factors examined in this age group (access to health care, poverty status, or educational level of the head of the household) were associated with the level of immunity to tetanus.

\section{Immunity to Tetanus in Relation to Disease Incidence}

Although the prevalence of immunity to tetanus declined rapidly starting at the age of 40 years, most of

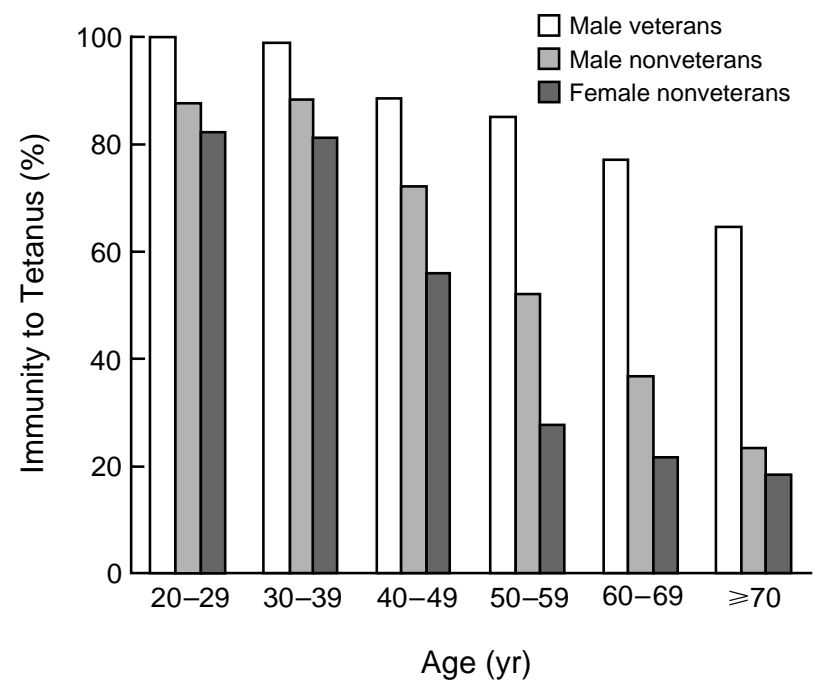

Figure 2. Age-Specific Prevalence of Immunity to Tetanus According to Military Status in the NHANES III Population, 1988 to 1991. the 107 cases of tetanus and 20 deaths from tetanus reported in 1989 and 1990 occurred in persons who were 60 years of age or older (Fig. 3).

\section{Discussion}

We used data from NHANES III to identify low rates of immunity to tetanus among the elderly, especially among older women. A history of military service was associated with substantially higher rates of immunity to tetanus, although the rates among male nonveterans were higher than those among female nonveterans. This may reflect the higher accident rate among men, since accidents increase the probability of receiving a tetanus booster.

The number of cases of tetanus has remained relatively stable, with 48 to 64 cases reported annually since $1986 .{ }^{19,22}$ For the period from 1979 to 1984 , the completeness of tetanus case reporting to the national surveillance system at the CDC was estimated to be between 22 percent and 46 percent. Thus, the total number of cases of tetanus in the United States may be two to four times higher than the number of cases reported to the $\mathrm{CDC} .{ }^{23}$

Most cases of tetanus in the United States occur among adults who are unvaccinated or whose history of vaccination is unknown. ${ }^{19}$ Earlier exposure to tetanus toxoid through the completion of a primary series of vaccinations may allow an anamnestic response on exposure to tetanus despite the presence of low circulating antibody levels. Other potential factors contributing to the low rate of morbidity include appropriate postexposure wound prophylaxis and decreased exposure to tetanus spores.

Although the rate of immunity to tetanus in schoolchildren in general exceeded 80 percent, this rate is 


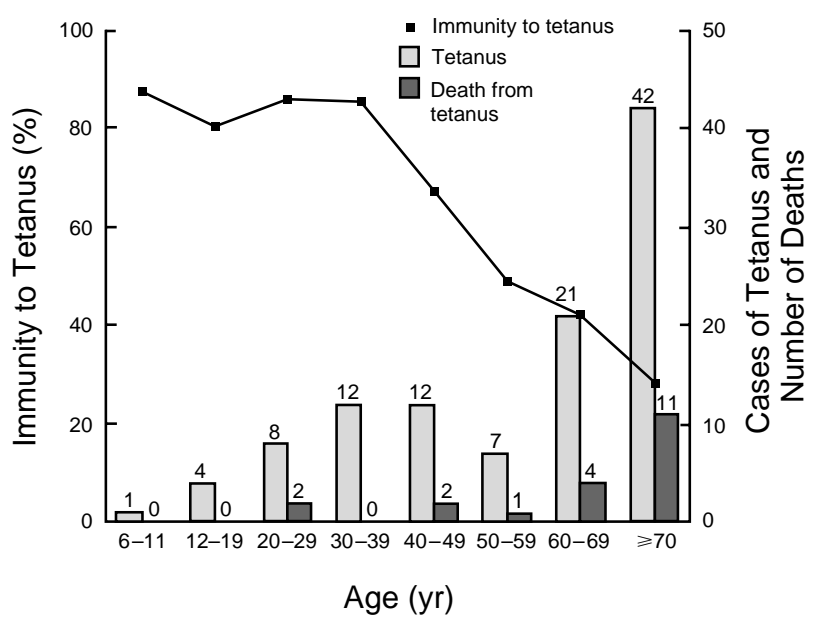

Figure 3. Age-Specific Prevalence of Immunity to Tetanus, Cases of Tetanus, and Deaths from Tetanus in the United States, 1989 to 1990.

much lower than the reported rate of 96 to 97 percent for the completion of three or more DTP immunizations at school entry. ${ }^{2}$ Several factors may contribute to this discrepancy. Over 99 percent of the school-age respondents in NHANES III attended school and therefore were subject to immunization laws. Less than 5 percent of parents requested that their children be exempted from these laws for religious or philosophical reasons (CDC: unpublished data). Therefore, exemption was not a major contributor to the lack of serologic immunity in the United States.

It is also possible that the rate of tetanus-vaccination coverage reported at school entry is an overestimate. However, this seems unlikely, since nearly all states rely on provider-reported immunization histories, which list the dates of each vaccination. Primary vaccine failure seems unlikely because tetanus toxoid is a very effective antigen, with a high level of response after only two immunizations. Ruben et al. ${ }^{24}$ found that 98.7 percent of children six months to two years of age who received two doses of DTP two months apart had protective levels of tetanus antibody. Myers et al. examined seroconversion rates in 48 patients 6 to 58 years of age. After the second immunization with tetanus toxoid, 100 percent had protective levels. ${ }^{25}$

Waning immunity after immunizations may account for the lack of protective antibody levels in some of the NHANES III respondents. Waning immunity is related to the antibody titer and the number of immunizations received. At least three vaccinations against tetanus are required to ensure adequate, long-lasting immunity. ${ }^{26}$ In one group of subjects 13 to 20 years of age who had been vaccinated 7 to 13 years earlier, the rate of immunity varied according to the number of immunizations received. Ninety-one percent of those who had received three injections were immune, 65 percent of those who had received two injections were immune, and 50 percent of those who had received one injection were immune. ${ }^{27}$ In a randomly selected sample of Danes 25 to 30 years of age who had received a primary series of three immunizations against tetanus but no booster vaccinations, 90 percent of those vaccinated less than 20 years earlier still had protective levels, and 72 percent of those vaccinated more than 25 years earlier were still protected. ${ }^{28}$

Given the results of the Danish study, children who receive three or more tetanus immunizations should not lose their protective levels for many years. The tetanus toxoid used in Denmark, however, is approximately 40 percent more potent than that used in the United States. Thus, in the United States, the three immunizations required by law for school entry may not provide lasting immunity. The recommendation of the Advisory Committee on Immunization Practices ${ }^{29}$ and the American Academy of Pediatrics ${ }^{30}$ for five immunizations by the age of six may be a more appropriate standard. In addition, a booster at adolescence is needed to ensure long-lasting immunity.

The absence of an association of immunity to tetanus with known risk factors (such as lower socioeconomic status, minority status, and birth outside the United States) among the group of children 6 to 16 years old is not surprising, given that school-entry requirements for vaccination apply to nearly all. The risk factors identified in children tend to apply only to the preschool-age group. ${ }^{2,31}$

The lack of protective immunity among older adults has been noted in the United States for the past several decades. ${ }^{3,4}$ In 1983, Weiss et al. ${ }^{4}$ reported protective levels of tetanus antibodies in only 54 percent of persons frequenting a senior-citizen center (mean age, 69 years) and 29 percent of patients in a convalescent hospital (mean age, 82 years). Military service has previously been associated with higher rates of protection against tetanus. ${ }^{4}$ Our findings corroborate the fact that very little has changed in the past 10 to 15 years.

The current recommendations are to give tetanus booster immunizations every 10 years to all adults. ${ }^{29,30}$ Some have argued that after the first booster dose, booster doses are needed only every 20 years to maintain immunity. ${ }^{32}$ Balestra and Littenberg ${ }^{33}$ have contended that a single booster dose at the age of 65 years to those who completed the primary series of immunizations in childhood would be a cost-effective strategy to decrease tetanus in adults. However, administering a primary series of tetanus toxoid (given with diphtheria toxoid) to elderly persons who have never been vaccinated may offer the best means of rapidly decreasing the tetanus burden in the United States.

\section{REFERENCES}

1. World Bank. World Development Report 1993: investing in health. New York: Oxford University Press, 1993:8.

2. Orenstein WA, Atkinson W, Mason D, Bernier RH. Barriers to vaccinating preschool children. J Health Care Poor Underserved 1990;1:315-30.

3. Crossley K, Irvine P, Warren JB, Lee BK, Mead K. Tetanus and diphtheria immunity in urban Minnesota adults. JAMA 1979;242:2298-300.

4. Weiss BP, Strassburg MA, Feeley JC. Tetanus and diphtheria immunity in an elderly population in Los Angeles county. Am J Public Health 1983;73: 802-4.

5. Public Health Service. State immunization requirements, 1993-1994. Atlanta: Centers for Disease Control and Prevention, 1993. 
6. Hinman AR. What will it take to fully protect all American children with vaccines? Am J Dis Child 1991;145:559-62

7. Vaccination coverage of 2-year-old children — United States, 1991-1992. MMWR Morb Mortal Wkly Rep 1994;42:985-8.

8. Vaccination coverage of 2-year-old children - United States, 1992-1993. MMWR Morb Mortal Wkly Rep 1994;43:282-3.

9. Vaccination coverage of 2-year-old children — United States, third quarter, 1993. MMWR Morb Mortal Wkly Rep 1994;43:556-9.

10. Reported vaccine-preventable diseases - United States, 1993, and the Childhood Immunization Initiative. MMWR Morb Mortal Wkly Rep 1994; 43:57-60.

11. Ezzati T, Khare M. Nonresponse adjustment in a national health survey. In: 1992 Proceedings of the Section on Survey Research Methods Section, Boston, August 9-13, 1992. Alexandria, Va.: American Statistical Association, 1993:339-44.

12. National Center for Health Statistics, Ezzati TM, Massey JT, et al. Sample design: Third National Health and Nutrition Examination Survey. Vital and health statistics. Series 2. No. 113. Washington, D.C.: Government Printing Office, 1992. (DHHS publication no. (PHS) 92-1387.)

13. Virella G, Hyman B. Quantitation of anti-tetanus and anti-diphtheria antibodies by enzymoimmunoassay: methodology and applications. J Clin Lab Anal 1991;5:43-8

14. Simonsen O, Bentzon MW, Heron I. ELISA for the routine determination of antitoxic immunity to tetanus. J Biol Stand 1986;14:231-9.

15. Bureau of the Census. Poverty in the United States: 1987. Current population reports. Series P-60. No. 163. Washington, D.C.: Government Printing Office, 1988.

16. Bureau of the Census. Poverty in the United States: 1988 and 1989. Current population reports. Series P-60. No. 171. Washington, D.C.: Government Printing Office, 1989.

17. Bureau of the Census. Poverty in the United States: 1990. Current population reports. Series P-60. No. 175. Washington, D.C.: Government Printing Office, 1991.

18. Khare M, Mohadjer LK, Ezzati-Rice TM, Waksberg J. An evaluation of nonresponse bias in NHANES III (1988-91). In: 1994 Proceedings of the Survey Research Methods Section of the American Statistical Association, Toronto, Aug. 13-18, 1994 (in press).

19. Prevots R, Sutter RW, Strebel PM, Cochi SL, Hadler S. Tetanus surveillance - United States, 1989-1990. MMWR CDC Surveill Summ 1992;41(SS-8): $1-9$.
20. Shah BV, Barnwell BG, Hunt P, Lavange LM. SUDAAN users' manual release 5.50. Research Triangle Park, N.C.: Research Triangle Institute, 1991.

21. Kahn HA, Sempos CT. Statistical methods in epidemiology. New York: Oxford University Press, 1989.

22. Summary of notifiable diseases - United States, 1992. MMWR Morb Mortal Wkly Rep 1992;41:67.

23. Sutter RW, Cochi SL, Brink EW, Sirotkin BI. Assessment of vital statistics and surveillance data for monitoring tetanus mortality, United States, 19791984. Am J Epidemiol 1990;131:132-42.

24. Ruben FL, Smith EA, Foster SO, et al. Simultaneous administration of smallpox, measles, yellow fever, and diphtheria-pertussis-tetanus antigens to Nigerian children. Bull World Health Organ 1973;48:175-81.

25. Myers MG, Beckman CW, Vosdingh RA, Hankins WA. Primary immunization with tetanus and diphtheria toxoids: reaction rates and immunogenicity in older children and adults. JAMA 1982;248:2478-80.

26. Simonsen O. Vaccination against tetanus and diphtheria: evaluations of immunity in the Danish population, guidelines for revaccination, and methods for control of vaccination programs. Dan Med Bull 1989;36:24-47.

27. Volk VK, Gottshall RY, Anderson HD, Top FH, Bunney WE, Serfling RE. Antigenic response to booster dose of diphtheria and tetanus toxoids: seven to thirteen years after primary inoculation of noninstitutionalized children. Public Health Rep 1962;77:185-94

28. Simonsen O, Kjeldsen K, Heron I. Immunity against tetanus and effect of revaccination 25-30 years after primary vaccination. Lancet 1984;2:12402.

29. General recommendations on immunization: recommendations of the Advisory Committee on Immunization Practices (ACIP). MMWR Morb Mortal Wkly Rep 1994;43(RR-1):1-38.

30. American Academy of Pediatrics. Tetanus (lockjaw). In: Peter G, ed. 1994 Red book: report of the Committee on Infectious Diseases. 23rd ed. Elk Grove Village, Ill.: American Academy of Pediatrics, 1994:458-63.

31. Marks JS, Halpin TJ, Irvin JJ, Johnson DA, Keller JR. Risk factors associated with failure to receive vaccinations. Pediatrics 1979;64:304-9.

32. Simonsen O, Badsberg JH, Kjeldsen K, Moller-Madsen B, Heron I. The falloff in serum concentration of tetanus antitoxin after primary and booster vaccination. Acta Pathol Microbiol Immunol Scand 1986;94:77-82.

33. Balestra DJ, Littenberg B. Should adult tetanus immunization be given as a single vaccination at age 65 ? A cost-effectiveness analysis. J Gen Intern Med 1993;8:405-12.

\section{IMAGES IN CLINICAL MEDICINE}

Images in Clinical Medicine, a weekly Journal feature, presents clinically important visual images, emphasizing those a doctor might encounter in an average day at the office, the emergency department, or the hospital. If you have an original unpublished, high-quality color or black-and-white photograph representing such a typical image that you would like considered for publication, send it with a descriptive legend to Kim Eagle, M.D., University of Michigan Medical Center, Division of Cardiology, 3910 Taubman Center, Box 0366, 1500 East Medical Center Drive, Ann Arbor, MI 48109. For details about the size and labeling of the photographs, the requirements for the legend, and authorship, please contact Dr. Eagle at 313-936-5275 (phone) or 313-936-5256 (fax), or the New England Journal of Medicine at images@edit.nejm.org (e-mail). 